\title{
A role for club cells in smoking-associated lung adenocarcinoma
}

\author{
Sabine J. Behrend $\mathbb{1}^{1,2}$, Georgia A. Giotopoulou ${ }^{1,2}$, Magda Spella ${ }^{3}$ and Georgios T. Stathopoulos $\mathbb{( 1}^{1,2}$ \\ ${ }^{1}$ Comprehensive Pneumology Center (CPC) and Institute for Lung Biology and Disease (iLBD); Helmholtz Center Munich-German \\ Research Center for Environmental Health (HMGU) and Ludwig-Maximilian-University (LMU) Munich, Munich, Germany. ${ }^{2}$ German \\ Center for Lung Research (DZL), Giessen, Germany. ${ }^{3}$ Laboratory for Molecular Respiratory Carcinogenesis, Dept of Physiology, Faculty \\ of Medicine, University of Patras, Patras, Greece.
}

Corresponding author: Georgios T. Stathopoulos (stathopoulos@helmholtz-muenchen.de)

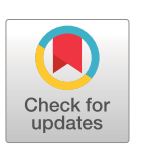

Copyright @The authors 2021

This version is distributed under the terms of the Creative Commons Attribution NonCommercial Licence 4.0. For commercial reproduction rights and permissions contact permissions@ersnet.org

Received: 22 May 2021 Accepted: 5 Aug 2021

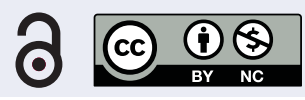

Shareable abstract (@ERSpublications)

Multiple lung epithelial cells are targets of carcinogenic hits. Club cells are such cells that can metabolically activate tobacco pre-carcinogens, being thus positioned as cells of origin of lung adenocarcinomas in smokers. https://bit.ly/3iOshcy

Cite this article as: Behrend SJ, Giotopoulou GA, Spella M, et al. A role for club cells in smokingassociated lung adenocarcinoma. Eur Respir Rev 2021; 30: 210122 [DOI: 10.1183/16000617.0122-2021].

\section{Abstract}

The cellular origin of lung adenocarcinoma remains a focus of intense research efforts. The marked cellular heterogeneity and plasticity of the lungs, as well as the vast variety of molecular subtypes of lung adenocarcinomas perplex the field and account for the extensive variability of experimental results. While most experts would agree on the cellular origins of other types of thoracic tumours, great controversy exists on the tumour-initiating cells of lung adenocarcinoma, since this histologic subtype of lung cancer arises in the distal pulmonary regions where airways and alveoli converge, occurs in smokers as well as nonsmokers, is likely caused by various environmental agents, and is marked by vast molecular and pathologic heterogeneity. Alveolar type II, club, and their variant cells have all been implicated in lung adenocarcinoma progeny and the lineage hierarchies in the distal lung remain disputed. Here we review the relevant literature in this rapidly expanding field, including results from mouse models and human studies. In addition, we present a case for club cells as cells of origin of lung adenocarcinomas that arise in smokers.

\section{Introduction}

Lung cancer is the most lethal cancer worldwide causing more than 1.7 million deaths in 2018 [1]. Lung adenocarcinoma (LUAD) is the most prevalent histologic subtype of lung cancer and accounts for almost half of all lung cancer deaths because of its indolent clinical presentation and its peripheral location in the lung parenchyma $[2,3]$. As most lung cancers, and especially LUAD, are diagnosed when they have already become locally advanced or metastatic, the 5-year survival rate amounts to only 15\% [4]. Despite rapid improvements in lung cancer prevention through smoking cessation and screening programmes, as well as targeted and multi-modality therapies in the last few decades, lung cancer remains a dreadful disease $[5,6]$. While the incidence and mortality of many other types of lung cancer such as squamous cell lung carcinoma and small cell lung carcinoma are continuously dropping in more developed countries where smoking incidence is declining, LUAD incidence and mortality are constantly rising, a phenomenon ascribed to the changing face of manufactured cigarettes and the increasing occurrence of LUAD in nonsmokers [7-12].

Cancers are defined by both their genetic alterations and their cells and tissues of origin [13]. These precancerous cells and tissues of origin define which cells can potentially lead to cancer, and are likely distinct from stem cells in established tumours, which constitute the subset of cancer cells that possesses stem cell characteristics and can drive tumour progression, therapy resistance, relapse and metastasis [13]. It has been demonstrated that self-renewal pathways such as Wnt, Hedgehog, and Notch that are upregulated in embryonic stem cells are also commonly reactivated in tumour-initiating and cancer stem cells as well as in mature lung cancers, driving proliferation, resistance to apoptosis, epithelial-to-mesenchymal transition, metastasis, acquisition of new blood vessels and further genomic permutation [14]. Such lung 
cancer initiating and stem cells possess self-renewal properties and are able to execute programmes of repair and normal tissue replacement during precarcinogenesis and established carcinogenesis [15].

Several cell types of the lungs hold tumour-initiating and stem cell properties and are thus potential cells of origin of lung cancer. To this end, p63(+)Krt5(+) distal airway stem cells likely relevant to airway basal cells have been shown to maintain and repopulate the airway and alveolar epithelium following viral injury, while club cell secretory protein (CCSP)-expressing club cells have also been shown to be capable of maintaining and repairing smaller bronchioles and alveolar structures [16-20]. Similarly, surfactant protein C (SFTPC)-producing alveolar type II (ATII) cells are responsible for maintenance of the alveolar epithelium [21, 22]. However, CCSP+SFTPC+ double positive bronchioalveolar stem cells (BASC) that reside in the terminal and respiratory bronchioles and alveolar ducts and can differentiate into club cells as well as alveolar cells were also shown to possess strong regenerative potential of both airway and alveolar epithelium [23]. An often underestimated and disputed pool of lung stem cells are of mesenchymal origin, located in all human tissues and organs and shown to migrate and differentiate into non-mesodermal cell types [24-26]. Additional cells that are lineage negative have been shown to reside in the lungs and to possess strong regenerative potential, while mesothelial cells were also shown to repopulate mesenchymal cells of the lungs and other internal organs [27, 28]. While lung stem cells and their functions are authoritatively reviewed elsewhere [29-33], the present review will summarise the current knowledge on the cells of origin of lung cancer with a special focus on club cells and their potential role as cancer stem cells of LUAD.

\section{Methods}

In addition to articles already known to the authors, PubMed (https://pubmed.ncbi.nlm.nih.gov/) was queried on 17 May 2021 using theterms: ('lung cancer’[Title/Abstract] OR 'lung adenocarcinoma'[Title/ Abstract] OR 'squamous cell lung carcinoma'[Title/Abstract] OR 'squamous cell lung cancer'[Title/ Abstract] OR ‘small cell lung cancer'[Title/Abstract] OR 'small cell lung carcinoma'[Title/Abstract]) AND ('stem cell’[Title/Abstract] OR 'cell of origin'[Title/Abstract]), retrieving 1385 results. Titles and journal names were manually curated to yield 416 articles whose abstracts were screened to yield the articles that built the knowledgebase and reference list of the present review.

\section{Results}

The causes of cancer translated to lung adenocarcinoma

Heredity causes multiple forms of cancer that can be clinically manifest in childhood, but also in adult life, and can be spontaneous or co-precipitated by germline mutations and environmental factors such as smoking [34, 35]. Heredity can also indirectly cause cancer by influencing our interactions with the environment, as is the case with a single nucleotide polymorphism in the habenular nicotinergic acetylcholine receptor which renders individuals susceptible to nicotine addiction and thereby to COPD, lung cancer and peripheral arterial disease [36]. Environmental carcinogens are thought to be even more important than heredity in precipitating chest tumours in humans. The relationship between tobacco smoking and lung cancer is one of the best documented epidemiologic relationships, while the same goes for asbestos exposure and mesothelioma [37-44]. Radiation has also been tightly linked with lung cancer development based on a number of different data sources, including atom bomb survivors, nuclear plant workers, uranium miners, radiotherapy patients, and participants of lung cancer screening programmes [45-54]. Finally, an increasingly stronger case is in the making for the connection between urban air pollution and lung cancer [55-58]. While the list of environmental carcinogens that impact the lungs and pleura is getting longer every day, and are comprehensively reviewed elsewhere [38], a fascinating new hypothesis saw the light of day in recent years: the bad luck hypothesis by TomasetTi and VogeLsTEIN examines the possibility of a significant proportion of human cancers resulting from stem cell divisions gone awry [59-62]. This ground-breaking work was based on measurements of cell division rates in the various organs using proliferating cell nuclear antigen (PCNA) and marker of proliferation Ki-67 staining of proliferating cells and extrapolation of the data by organ size and cell number. Indeed, PCNA+ cells in the resting lung are very sparse, and increase tremendously in lung cancers [59-62].

Hence, several different environmental and endogenous causes can precipitate lung cancer originating from the same and/or different lung lineages, and this heterogeneity is most evident with LUAD. It is highly likely that different molecular subtypes of LUAD exist, which emanate from different cells of origin that were tumour-initiated by different triggers, and such patient subgroups are evident in molecular and epidemiologic datasets. For example, we identified two subgroups of patients with LUAD in atom bomb survivors from Hiroshima and Nagasaki included in the Life Span Study that can be explained by exposures to smoking and to irradiation, and validated their existence in the TCGA cohort from the US [48]. In addition, molecular subsets of KRAS-mutant LUAD were identified within the TCGA cohort via elegant 
genomic analyses [63]. This interpatient heterogeneity of LUAD needs to be addressed by future studies on the cell of origin of lung tumours, which should ascertain the tumour subtype under study.

\section{Evidence from genetic mouse models of LUAD}

Studies on the origins of LUAD have been boosted tremendously by the use of genetically engineered mouse models, which are valuable tools for tumour induction and lineage tracing. Model organisms have been genetically manipulated to conditionally express oncogenic or tumour suppressive alleles, in conjunction with CRE recombinase expressed under the control of a promoter active specifically in one of the different respiratory cell lineages, and are therefore ideal for the tracing of a specific cell population carrying specific mutations in time and space. Prominent focus has been given to the development of mouse models harbouring KRAS proto-oncogene GTPase (encoded by the human KRAS and the murine Kras genes) and tumour protein 53 (encoded by the human TP53 and the murine Trp53 genes) mutations, as oncogenic mutations of the KRAS and TP53 genes are found in 34\% and 54\% of human LUAD [64, 65]. As a result, several mutant Kras/KRAS knock-in and Trp53 knockout mouse models have been generated, with the most widely used among them being the Lox-Stop-Lox-KRAS ${ }^{\mathrm{G} 12 \mathrm{D}}$ model, which develops LUAD within 4 months post intranasal administration of adenoviral CRE, and the Lox-Trp53-Lox model, in which Trp53 can be deleted in specific lineages and can cause more aggressive LUAD when combined with the Lox-Stop-Lox-KRAS ${ }^{\mathrm{G} 12 \mathrm{D}}$ model, as well as other transgenic mouse models that cannot be all mentioned here [64-68]. Pulmonary lineage tracing studies in the respiratory epithelium of these genetically modified mice following forced expression of the $\mathrm{Kras}^{\mathrm{G} 12 \mathrm{D}}$ mutation in club airway epithelial cells expressing CCSP, or in ATII alveolar epithelial cells expressing SFTPC, or in bronchoalveolar epithelial cells expressing both markers, resulted interchangeably in LUAD formation, leading to inconclusive data as to the progenitors of LUAD in adult mice [22, 23, 69-71]. This is partly attributable to the fact that some of the above-referenced lineage tracing mouse models feature incomplete and/or promiscuous lung cell labelling, to the heterogeneity among ATII cells regarding their proliferative and to tumour-initiating cell properties [22], but also to the viral-induced injury itself, since it was also shown that adenoviral infection alone contributed to the transformation of lung cells towards LUAD [71]. Similar genetically engineered mouse models reproducing other LUAD driver mutations such as EGFR mutations and EML4-ALK fusions have also been established and have proven the oncogenicity of the respective molecular changes when forcefully expressed in alveolar cells, implying that ATII cells are the cellular origins of multiple oncogene-driven LUAD tumours [72-74].

\section{Evidence from environmental LUAD induction in mice}

Although the above-referenced genetic mouse models have enhanced our mechanistic understanding of LUAD development, oncogene function and cell of origin, they do not fully capture the mutation diversity and burden of human LUAD, which is caused by environmental carcinogens rather than single oncogenes $[74,75]$. To better recapitulate the mutational acquisition pattern and dissect the complex pathobiology of human LUAD, alternative strategies can be employed that combine conditional respiratory lineage tracing with carcinogenic insults. This approach is advantageous in recapitulating pathophysiologic endogenous carcinogenic events and in unravelling key events taking place during early tumour initiation, knowledge which can prove valuable for the development of LUAD early detection of chemoprevention strategies. Along these lines, we recently showed that as early as two weeks following treatment of lineage-marked mice with urethane (ethyl carbamate, a chemical carcinogen contained in tobacco smoke) [76], Kras ${ }^{\mathrm{Q} 61 \mathrm{R}}$ driver mutations accumulate specifically in club and not in ATII cells [20], in line with evidence from human airway epithelial cells found to be sensitised by tobacco smoke to a single-hit KRAS mutation [77] and from a massive parallel sequencing approach [78]. These results are also in accord with earlier studies that dictate that only club cells possess the cytochrome CYP2E1 [79, 80] that is required to convert the tobacco pre-carcinogen urethane (ethyl carbamate) to carcinogenic derivatives vinyl carbamate and its epoxide [81, 82], which in turn have a half-life of a few femtoseconds and can thus only injure the DNA of the same cell that metabolically activates them [83, 84]. Thus, club cells are likely to be the cellular source of LUAD triggered by the tobacco carcinogen urethane as opposed to ATII cells as cells of origin of transgenic lung tumours in mice [20,85].

Indeed, environmental-induced LUAD in susceptible inbred mouse strains is a versatile research tool. To this end, single-hit LUAD emerge in sensitive FVB and A/J mice 6-9 months post-treatment with intraperitoneal urethane (ethyl carbamate), N-nitrosodiethylamine (DEN), 4-(methylnitrosamino)-1(3-pyridyl)-1-butanone (NNK), N'-nitrosonornicotine (NNN), and N-methyl-N-nitrosourea (MNU), and uniquely recapitulate the mutational landscape of human LUAD [20, 75, 86-93]. Such models have been successfully used to study oncogene function in the genomic context and to reproduce human-relevant LUAD mutanomes in mice [75, 93]. Although chemical models of LUAD do not necessarily rely on human-relevant Kras mutations, they rather generate a human-relevant mutation spectrum in terms of 
single nucleotide variants in the mono- and tri-nucleotide, as well as the gene contexts [75, 87]. For example, urethane-induced LUAD in mice feature the $\operatorname{Kras}^{\mathrm{Q} 61 \mathrm{R}}$ mutation, which is very rare in human LUAD, but at the same time they harbour multiple mutations in critical LUAD genes such as Alk and Crebbp that are highly relevant to human LUAD [75]. Combining such tools with lineage tracing allows spatiotemporal exploration of whole adverse outcome pathways leading from a specific carcinogen to lineage-restricted molecular initiating events, key progression events and clinicopathologic and molecular signatures that indicate the initiating agent and cell type. Using such an approach, club cells were shown to contribute to lung maintenance, repair and carcinogenesis, to possess stem cell features and to sustain chemical-induced KRAS mutations as LUAD cells of origin would [20, 85].

\section{Evidence from human LUAD}

Human LUAD patient cohorts have also been interrogated for cell of origin signatures, since abundant evidence supports that cell of origin is imprinted and deductible from molecular data [94, 95]. These studies have been sparse but imperative, since there are marked differences between mouse and human lung epithelial cell biology, rendering translation of mouse lineage tracing data to the human setting uncertain. Such studies are marked by inherent uncertainty, since lineage plasticity in the lungs is tremendous and even malignant lung tumours can switch histology and molecular profiles upon acquisition of new genomic alterations [96, 97]. To this end, one study exploited the finding of co-mutations of KRAS and KEAP1 in 5\% of LUAD [63] to ascribe different cells of origin (airway versus alveolar), as well as immunometabolic profiles to KRAS-mutant LUAD with or without KEAP1 alterations [98]. In another effort to determine genomic imprints of cell fate, squamous and adenomatous lung tumours appeared highly similar, suggesting a common ancestor [99]. In our view, tumours of smokers and nonsmokers may very well have different cellular origins, and hence studies should focus on molecular hallmarks of smoking when examining lineage of origin, since such markers have been described, including KRAS and TP53 mutations, as well as the C>A transversions described elsewhere [100-102]. These data show the need for genetic lineage tracing models in the search for cells of origin of lung tumours, and for biomarkers of environmental and endogenous lung cancer causative agents. Furthermore, they illustrate the marked heterogeneity of LUAD, which needs to be taken into account in such lineage tracing studies.

\section{Conclusions}

The contribution of cells with stemness properties to tissue homeostasis, regeneration and tumour progression is undeniable, and this trait renders them attractive therapeutic targets. In heterogeneous tumours, stem cells will sustain tumour growth and possibly tumour recurrence. Chemical carcinogenesis mouse models faithfully recapitulate human LUAD, and have highlighted club cells as a central respiratory cell population with a key role in early initiation events leading to LUAD. Future perspectives should therefore be targeted to better characterise this cell type and to increase our comprehension of the mechanisms regulating cell biology, biomarker expression, mutational acquisition spatiotemporal patterns, molecular dynamics of tumour evolution and tumour architecture. Novel technologies, such as organoids, 3D whole organ imaging with single cell resolution, and single cell sequencing, have been developed to compliment the knowledge gained from transgenic mouse models and better understand the underlying tumour pathobiology. The new knowledge should be tested on human-relevant experimental pre-clinical models, so that effective therapies can be developed.

Acknowledgements: This work was supported by the Graduate College (Graduiertenkolleg, GRK) \#2338 of the German Research Society (Deutsche Forschungsgemeinschaft, DFG), the target validation project for pharmaceutical development ALTERNATIVE of the German Ministry for Education and Research (Bundesministerium für Bildung und Forschung, BMBF), and a Translational Research Grant by the German Centre for Lung Research (Deutsches Zentrum für Lungenforschung, DZL) (all to GTS); the Greek State Scholarship Foundation Program 'Reinforcement of Postdoctoral Researchers-1st and 2nd cycles' co-financed by the European Union Social Fund and Greek national funds (NSRF 2014-2020 and MIS-5033021) and General Secretariat for Research and Innovation and Hellenic Foundation for Research and Innovation grant \#1853a (all to MS).

Provenance: Commissioned article, peer reviewed.

Author Contributions: S.J. Behrend, G.A. Giotopoulou, M. Spella and G.T. Stathopoulos conceived the idea, analysed data, generated graphs and figures, and wrote the paper. All authors reviewed and concurred with the submitted manuscript.

Conflict of interest: None declared. 
Support statement: Funding was received from Bundesministerium für Bildung und Forschung (Grant: ALTERNATIVE), Deutsches Zentrum für Lungenforschung (Grant: Translational Research Grant), Greek State Scholarship Foundation Program 'Reinforcement of Postdoctoral Researchers-1st and 2nd cycles' co-financed by the European Union Social Fund and Greek national funds (Grant: NSRF 2014-2020 and MIS-5033021), General Secretariat for Research and Innovation and Hellenic Foundation for Research and Innovation (Grant: \#1853a) and Deutsche Forschungsgemeinschaft (Grant: GRK2338). Funding information for this article has been deposited with the Crossref Funder Registry.

\section{References}

1 Bray F, Ferlay J, Soerjomataram I, et al. Global cancer statistics 2018: GLOBOCAN estimates of incidence and mortality worldwide for 36 cancers in 185 countries. CA Cancer J Clin 2018; 68: 394-424.

2 Houston KA, Henley SJ, Li J, et al. Patterns in lung cancer incidence rates and trends by histologic type in the United States, 2004-2009. Lung Cancer 2014; 86: 22-28.

3 Kenfield SA, Wei EK, Stampfer MJ, et al. Comparison of aspects of smoking among the four histological types of lung cancer. Tob Control 2008; 17: 198-204.

4 Minna JD, Schiller JH. Lung Cancer. In: Harrison's Principles of Internal Medicine. 17th Edn. MacGraw-Hill, Philadelphia, 2008; pp. 551-562.

5 Schabath MB, Cote ML. Cancer progress and priorities: lung cancer. Cancer Epidemiol Biomarkers Prev 2019; 28: 1563-1579.

6 Hirsch FR, Scagliotti GV, Mulshine JL, et al. Lung cancer: current therapies and new targeted treatments. Lancet 2017; 389: 299-311.

7 Janssen-Heijnen ML, Nab HW, van Reek J, et al. Striking changes in smoking behaviour and lung cancer incidence by histological type in south-east Netherlands, 1960-1991. Eur J Cancer 1995; 31a: 949-952.

8 Levi F, Franceschi S, La Vecchia C, et al. Lung carcinoma trends by histologic type in Vaud and Neuchâtel, Switzerland, 1974-1994. Cancer 1997; 79: 906-914.

9 Russo A, Crosignani P, Franceschi S, et al. Changes in lung cancer histological types in Varese Cancer Registry, Italy 1976-1992. Eur J Cancer 1997; 33: 1643-1647.

10 Wingo PA, Ries LA, Giovino GA, et al. Annual report to the nation on the status of cancer, 1973-1996, with a special section on lung cancer and tobacco smoking. J Natl Cancer Inst 1999; 91: 675-690.

11 Sobue T, Ajiki W, Tsukuma H, et al. Trends of lung cancer incidence by histologic type: a population-based study in Osaka, Japan. Jpn J Cancer Res 1999; 90: 6-15.

12 Cha Q, Chen Y, Du Y. The trends in histological types of lung cancer during 1980-1988, Guangzhou, China. Lung Cancer 1997; 17: 219-230.

13 Batlle E, Clevers H. Cancer stem cells revisited. Nat Med 2017; 23: 1124-1134.

14 Lundin A, Driscoll B. Lung cancer stem cells: progress and prospects. Cancer Lett 2013; 338: 89-93.

15 Heng WS, Gosens R, Kruyt FAE. Lung cancer stem cells: origin, features, maintenance mechanisms and therapeutic targeting. Biochem Pharmacol 2019; 160: 121-133.

16 Rock JR, Onaitis MW, Rawlins EL, et al. Basal cells as stem cells of the mouse trachea and human airway epithelium. Proc Natl Acad Sci USA 2009; 106: 12771-12775.

17 Rawlins EL, Okubo T, Xue Y, et al. The role of Scgb1a1+ Clara cells in the long-term maintenance and repair of lung airway, but not alveolar, epithelium. Cell Stem Cell 2009; 4: 525-534.

18 Zheng D, Limmon GV, Yin L, et al. Regeneration of alveolar type I and II cells from Scgb1a1- expressing cells following severe pulmonary damage induced by bleomycin and influenza. PLOS ONE 2012; 7: e48451.

19 Zuo W, Zhang T, Wu DZ, et al. p63(+) Krt5(+) distal airway stem cells are essential for lung regeneration. Nature 2015; 517: 616-620.

20 Spella M, Lilis I, Pepe MA, et al. Club cells form lung adenocarcinomas and maintain the alveoli of adult mice. Elife 2019; 8: e45571.

21 Barkauskas CE, Cronce MJ, Rackley CR, et al. Type 2 alveolar cells are stem cells in adult lung. J Clin Invest 2013; 123: 3025-3036.

22 Desai TJ, Brownfield DG, Krasnow MA. Alveolar progenitor and stem cells in lung development, renewal and cancer. Nature 2014; 507: 190-194.

$23 \mathrm{Kim}$ CF, Jackson EL, Woolfenden AE, et al. Identification of bronchioalveolar stem cells in normal lung and lung cancer. Cell 2005; 121: 823-835.

24 Chamberlain G, Fox J, Ashton B, et al. Concise review: mesenchymal stem cells: their phenotype, differentiation capacity, immunological features, and potential for homing. Stem Cells 2007; 25: 2739-2749.

25 Kotton DN, Ma BY, Cardoso WV, et al. Bone marrow-derived cells as progenitors of lung alveolar epithelium. Development 2001; 128: 5181-5188.

26 Lee JH, Tammela T, Hofree M, et al. Anatomically and functionally distinct lung mesenchymal populations marked by Lgr5 and Lgr6. Cell 2017; 170: 1149-1163.

27 Vaughan AE, Brumwell AN, Xi Y, et al. Lineage-negative progenitors mobilize to regenerate lung epithelium after major injury. Nature 2015; 517: 621-625. 
Rinkevich Y, Mori T, Sahoo D, et al. Identification and prospective isolation of a mesothelial precursor lineage giving rise to smooth muscle cells and fibroblasts for mammalian internal organs, and their vasculature. Nat Cell Biol 2012; 14: 1251-1260.

Wu H, Tang N. Stem cells in pulmonary alveolar regeneration. Development 2021; 148: dev193458.

Nadkarni RR, Abed S, Draper JS. Stem cells in pulmonary disease and regeneration. Chest 2018; 153: 994-1003.

Tata PR, Rajagopal J. Plasticity in the lung: making and breaking cell identity. Development 2017; 144 755-766.

Chen F, Fine A. Stem cells in lung injury and repair. Am J Pathol 2016; 186: 2544-2550.

Leeman KT, Fillmore CM, Kim CF. Lung stem and progenitor cells in tissue homeostasis and disease. Curr Top Dev Biol 2014; 107: 207-233.

Sweet-Cordero EA, Biegel JA. The genomic landscape of pediatric cancers: Implications for diagnosis and treatment. Science 2019; 363: 1170-1175.

Nenekidis I, Stathopoulos GT, Anagnostakou V, et al. Atypical pulmonary carcinoid tumour in a 28-year-old nonsmoker with Prader-Willi syndrome. Eur Respir J 2011; 38: 1230-1233.

Thorgeirsson TE, Geller F, Sulem P, et al. A variant associated with nicotine dependence, lung cancer and peripheral arterial disease. Nature 2008; 452: 638-642.

Hecht SS. Tobacco smoke carcinogens and lung cancer. J Natl Cancer Inst 1999; 91: 1194-1210.

Alberg AJ, Brock MV, Ford JG, et al. Epidemiology of lung cancer: Diagnosis and management of lung cancer, 3rd ed: American College of Chest Physicians evidence-based clinical practice guidelines. Chest 2013; 143: Suppl 5, e1S-e29S.

Sun S, Schiller JH, Gazdar AF. Lung cancer in never smokers - a different disease. Nat Rev Cancer 2007; 7 : 778-790.

Rudin CM, Brambilla E, Faivre-Finn C, et al. Small-cell lung cancer. Nat Rev Dis Primers 2021; 7: 3.

Bibby AC, Tsim S, Kanellakis N, et al. Malignant pleural mesothelioma: an update on investigation, diagnosis and treatment. Eur Respir Rev 2016; 25: 472-486.

Liu B, van Gerwen M, Bonassi S, et al. Epidemiology of environmental exposure and malignant mesothelioma. J Thorac Oncol 2017; 12: 1031-1045.

Tsao AS, Wistuba I, Roth JA, et al. Malignant pleural mesothelioma. J Clin Oncol 2009; 27: 2081-2090.

Yap TA, Aerts JG, Popat S, et al. Novel insights into mesothelioma biology and implications for therapy. Nat Rev Cancer 2017; 17: 475-488.

Brenner DJ, Doll R, Goodhead DT, et al. Cancer risks attributable to low doses of ionizing radiation: assessing what we really know. Proc Natl Acad Sci USA 2003; 100: 13761-13766.

Darby SC, Doll R, Gill SK, et al. Long term mortality after a single treatment course with X-rays in patients treated for ankylosing spondylitis. Br J Cancer 1987; 55: 179-190.

Sachs RK, Brenner DJ. Solid tumor risks after high doses of ionizing radiation. Proc Natl Acad Sci USA 2005; 102: 13040-13045.

Castelletti N, Kaiser JC, Simonetto C, et al. Risk of lung adenocarcinoma from smoking and radiation arises in distinct molecular pathways. Carcinogenesis 2019; 40: 1240-1250.

Furukawa K, Preston DL, Lönn S, et al. Radiation and smoking effects on lung cancer incidence among atomic bomb survivors. Radiat Res 2010; 174: 72-82.

Egawa H, Furukawa K, Preston D, et al. Radiation and smoking effects on lung cancer incidence by histological types among atomic bomb survivors. Radiat Res 2012; 178: 191-201.

McCunney RJ, Li J. Radiation risks in lung cancer screening programs: a comparison with nuclear industry workers and atomic bomb survivors. Chest 2014; 145: 618-624.

Lubin JH, Boice JD Jr, Edling C, et al. Lung cancer in radon-exposed miners and estimation of risk from indoor exposure. $J$ Natl Cancer Inst 1995; 87: 817-827.

Darby S, Hill D, Auvinen A, et al. Radon in homes and risk of lung cancer: collaborative analysis of individual data from 13 European case-control studies. BMJ 2005; 330: 223.

Gray A, Read S, McGale P, et al. Lung cancer deaths from indoor radon and the cost effectiveness and potential of policies to reduce them. BMJ 2009; 338: a3110.

Eckel SP, Cockburn M, Shu YH, et al. Air pollution affects lung cancer survival. Thorax 2016; 71: 891-898.

Moore JX, Akinyemiju T, Wang HE. Pollution and regional variations of lung cancer mortality in the United States. Cancer Epidemiol 2017; 49: 118-127.

5 Raaschou-Nielsen O, Andersen ZJ, Beelen R, et al. Air pollution and lung cancer incidence in 17 European cohorts: prospective analyses from the European Study of Cohorts for Air Pollution Effects (ESCAPE). Lancet Oncol 2013; 14: 813-822.

58 Seow WJ, Shu XO, Nicholson JK, et al. Association of untargeted urinary metabolomics and lung cancer risk among never-smoking women in China. JAMA Netw Open 2019; 2: e1911970.

Tomasetti C, Li L, Vogelstein B. Stem cell divisions, somatic mutations, cancer etiology, and cancer prevention. Science 2017; 355: 1330-1334. 
Tomasetti C, Vogelstein B. Cancer etiology. Variation in cancer risk among tissues can be explained by the number of stem cell divisions. Science 2015; 347: 78-81.

Tomasetti C, Poling J, Roberts NJ, et al. Cell division rates decrease with age, providing a potentia explanation for the age-dependent deceleration in cancer incidence. Proc Natl Acad Sci USA 2019; 116: 20482-20488.

Tomasetti C, Durrett R, Kimmel M, et al. Role of stem-cell divisions in cancer risk. Nature 2017; 548: E13-E14.

Skoulidis F, Byers LA, Diao L, et al. Co-occurring genomic alterations define major subsets of KRAS-mutan lung adenocarcinoma with distinct biology, immune profiles, and therapeutic vulnerabilities. Cancer Discov 2015; 5: 860-877.

Jackson EL, Willis N, Mercer K, et al. Analysis of lung tumor initiation and progression using conditional expression of oncogenic K-ras. Genes Dev 2001; 15: 3243-3248.

Meylan E, Dooley AL, Feldser DM, et al. Requirement for NF-kappaB signalling in a mouse model of lung adenocarcinoma. Nature 2009; 462: 104-107.

Xue W, Meylan E, Oliver TG, et al. Response and resistance to NF-kB inhibitors in mouse models of lung adenocarcinoma. Cancer Discov 2011; 1: 236-247.

Jackson EL, Olive KP, Tuveson DA, et al. The differential effects of mutant p53 alleles on advanced murine lung cancer. Cancer Res 2005; 65: 10280-10288.

Ventura A, Kirsch DG, McLaughlin ME, et al. Restoration of p53 function leads to tumour regression in vivo. Nature 2007; 445: 661-665.

Sutherland KD, Song JY, Kwon MC, et al. Multiple cells-of-origin of mutant K-Ras-induced mouse lung adenocarcinoma. Proc Natl Acad Sci USA 2014; 111: 4952-4957.

Mainardi S, Mijimolle N, Francoz S, et al. Identification of cancer initiating cells in K-Ras driven lung adenocarcinoma. Proc Natl Acad Sci USA 2014; 111: 255-260.

Guerra C, Mijimolle N, Dhawahir A, et al. Tumor induction by an endogenous K-ras oncogene is highly dependent on cellular context. Cancer Cell 2003; 4: 111-120.

Politi K, Zakowski MF, Fan PD, et al. Lung adenocarcinomas induced in mice by mutant EGF receptors found in human lung cancers respond to a tyrosine kinase inhibitor or to down-regulation of the receptors. Genes Dev 2006; 20: 1496-1510.

Soda M, Takada S, Takeuchi K, et al. A mouse model for EML4-ALK-positive lung cancer. Proc Natl Acad Sci USA 2008; 105: 19893-19897.

McFadden DG, Politi K, Bhutkar A, et al. Mutational landscape of EGFR-, MYC-, and Kras-driven genetically engineered mouse models of lung adenocarcinoma. Proc Natl Acad Sci USA 2016; 113: E6409-E6417.

Westcott PM, Halliwill KD, To MD, et al. The mutational landscapes of genetic and chemical models of Kras-driven lung cancer. Nature 2015; 517: 489-492.

Schmeltz I, Chiong KG, Hoffmann D. Formation and determination of ethyl carbamate in tobacco and tobacco smoke. J Anal Toxicol 1978; 2: 265-268.

Vaz M, Hwang SY, Kagiampakis I, et al. Chronic cigarette smoke-induced epigenomic changes precede sensitization of bronchial epithelial cells to single-step transformation by KRAS mutations. Cancer Cell 2017; 32: $360-376$.

Li S, MacAlpine DM, Counter CM. Capturing the primordial Kras mutation initiating urethane carcinogenesis. Nat Commun 2020; 11: 1800.

Forkert PG. CYP2E1 is preferentially expressed in Clara cells of murine lung: localization by in situ hybridization and immunohistochemical methods. Am J Respir Cell Mol Biol 1995; 12: 589-596.

Hukkanen J, Pelkonen O, Hakkola J, et al. Expression and regulation of xenobiotic-metabolizing cytochrome P450 (CYP) enzymes in human lung. Crit Rev Toxicol 2002; 32: 391-411.

Guengerich FP, Kim DH, Iwasaki M. Role of human cytochrome p-450 IIE1 in the oxidation of many low molecular weight cancer suspects. Chem Res Toxicol 1991; 4: 168-179.

Forkert PG. Mechanisms of lung tumorigenesis by ethyl carbamate and vinyl carbamate. Drug Metab Rev 2010; 42: 355-378.

Dahl GA, Miller JA, Miller EC. Vinyl carbamate as a promutagen and a more carcinogenic analog of ethyl carbamate. Cancer Res 1978; 38: 3793-3804.

8 Park KK, Liem A, Stewart BC, et al. Vinyl carbamate epoxide, a major strong electrophilic, mutagenic and carcinogenic metabolite of vinyl carbamate and ethyl carbamate (urethane). Carcinogenesis 1993; 14: 441-450.

Spella M, Lilis I, Stathopoulos GT. Shared epithelial pathways to lung repair and disease. Eur Respir Rev 2017; 26: 170048.

Stathopoulos GT, Sherrill TP, Cheng DS, et al. Epithelial NF-kappaB activation promotes urethane-induced lung carcinogenesis. Proc Natl Acad Sci USA 2007; 104: 18514-18519.

Kanellakis NI, Giannou AD, Pepe MAA, et al. Tobacco chemical-induced mouse lung adenocarcinoma cell lines pin the prolactin orthologue proliferin as a lung tumour promoter. Carcinogenesis 2019; 40: 1352-1362. 
Vreka M, Lilis I, Papageorgopoulou M, et al. IкB Kinase $\alpha$ is required for development and progression of KRAS-mutant lung adenocarcinoma. Cancer Res 2018; 78: 2939-2951.

Murphy SE, Isaac IS, Ding X, et al. Specificity of cytochrome P450 2A3-catalyzed alpha-hydroxylation of N'-nitrosonornicotine enantiomers. Drug Metab Dispos 2000; 28: 1263-1266.

Wong HL, Murphy SE, Hecht SS. Cytochrome P450 2A-catalyzed metabolic activation of structurally similar carcinogenic nitrosamines: $\mathrm{N}$ '-nitrosonornicotine enantiomers, $\mathrm{N}$-nitrosopiperidine, and $\mathrm{N}$-nitrosopyrrolidine. Chem Res Toxicol 2005; 18: 61-69.

Xue J, Yang S, Seng S. Mechanisms of cancer induction by tobacco-specific NNK and NNN. Cancers (Basel) 2014; 6: 1138-1156.

Yuan JM, Knezevich AD, Wang $\mathrm{R}$, et al. Urinary levels of the tobacco-specific carcinogen $\mathrm{N}^{\prime}$-nitrosonornicotine and its glucuronide are strongly associated with esophageal cancer risk in smokers. Carcinogenesis 2011; 32: 1366-1371.

To MD, Wong CE, Karnezis AN, et al. Kras regulatory elements and exon 4A determine mutation specificity in lung cancer. Nat Genet 2008; 40: 1240-1244.

Hoadley KA, Yau C, Hinoue T, et al. Cell-of-origin patterns dominate the molecular classification of 10,000 tumors from 33 types of cancer. Cell 2018; 173: 291-304.e6.

Sproul D, Kitchen RR, Nestor CE, et al. Tissue of origin determines cancer-associated CpG island promoter hypermethylation patterns. Genome Biol 2012; 13: R84.

Zhang $\mathrm{H}$, Fillmore Brainson $\mathrm{C}$, Koyama $\mathrm{S}$, et al. Lkb1 inactivation drives lung cancer lineage switching governed by polycomb repressive complex 2. Nat Commun 2017; 8: 14922.

van Veen JE, Scherzer M, Boshuizen J, et al. Mutationally-activated PI3'-kinase- $\alpha$ promotes de-differentiation of lung tumors initiated by the BRAF ${ }^{\mathrm{V} 600 \mathrm{E}}$ oncoprotein kinase. Elife 2019; 8: e43668.

Best SA, Ding S, Kersbergen A, et al. Distinct initiating events underpin the immune and metabolic heterogeneity of KRAS-mutant lung adenocarcinoma. Nat Commun 2019; 10: 4190.

Tonon G, Brennan C, Protopopov A, et al. Common and contrasting genomic profiles among the major human lung cancer subtypes. Cold Spring Harb Symp Quant Biol 2005; 70: 11-24.

Alexandrov LB, Nik-Zainal S, Wedge DC, et al. Signatures of mutational processes in human cancer. Nature 2013; 500: 415-421.

Govindan R, Ding L, Griffith M, et al. Genomic landscape of non-small cell lung cancer in smokers and never-smokers. Cell 2012; 150: 1121-1134.

Alexandrov LB, Ju YS, Haase $\mathrm{K}$, et al. Mutational signatures associated with tobacco smoking in human cancer. Science 2016; 354: 618-622. 